\title{
LIMITING ULTRASYMMETRIC SEQUENCE SPACES
}

\author{
PEDRo FERnÁndeZ-MARTínez AND TERESA Signes
}

Abstract. The paper gives an analytic characterization of a class of ultrasymmetric sequence spaces that are very close to $\ell_{\infty}$. We introduce discrete descriptions of limiting $J$ and $K$ interpolation methods, and we apply the results and the techniques developed to the study of limiting approximation spaces.

Mathematics subject classification (2010): 46B70, 46E30, 47B38.

Keywords and phrases: Sequence spaces, ultrasymmetric spaces, interpolation theory, approximation spaces.

\section{REFERENCES}

[1] I. Ahmed, D. E. Edmunds, W. D. Evans And G. E. Karadzhov, Reiteration theorems for the $K$-interpolation method in limiting cases, Math. Nachr. 284 (2011), no. 4, 421-442.

[2] S. Astashin and L. Maligranda, Ultrasymmetric Orlicz spaces., J. Math. Anal. Appl. 1 (2008), 273-285.

[3] C. Bennett And R. Sharpley, Interpolation of operators, Pure and Applied Mathematics, vol. 129, Academic Press, Inc., Boston, MA, 1988.

[4] J. BERGH AND J. LÖFströM, Interpolation spaces. An introduction, Springer, Berlin-HeidelbergNew York, 1976.

[5] P. L. Butzer And K. Scherer, Approximationsprozesse und interpolationsmethoden, Bibliographisches Institut, Mannheim-Zürich, 1968.

[6] F. Cobos And O. DomingueZ, Approximation spaces, limiting interpolation and Besov spaces, J. Approx. Theory 189 (2015), 43-36.

[7] F. Cobos, L. M. Fernández Cabrera, T. KÜHn And T. Ullrich, On an extreme class of real interpolation spaces, J. Funct. Anal. 256 (2009), 2321-2366.

[8] F. Cobos And L. M. Fernández-Cabrera And A. Martínez, On a paper of Edmunds and Opic on limiting interpolation of compact operators between $L_{p}$ spaces, Math. Nachr. 288 (2015), no. $2-3,167-175$.

[9] F. Cobos And L. M. FernándeZ-Cabrera And M. Mastylo, Abstract limit J-spaces, J. London Math. Soc. 82 (2010), 83-101.

[10] F. Cobos and L. M. Fernández-Cabrera And P. Silvestre, Limiting J -spaces for general couples, Z. Anal. Anwend. 32 (2013), no. 1, 3696-3722.

[11] F. Cobos and L. M. Fernández-Cabrera And P. Silvestre, New limiting real interpolation methods and their connection with the methods associated to the unit square, Math. Nachr. 286 (2013), no. 5-6, 569-578.

[12] F. CoBos AND T. KÜHN, Equivalence of $K$ - and $J$-methods for limiting real interpolation spaces, J. Funct. Anal. 216 (2011), 3696-3722.

[13] F. Cobos And M. Milman, On a limit class of approximation spaces, Numer. Funct. Anal. Optim. 11 (1990), no. 1-2, 11-31.

[14] F. Cobos AND I. ResinA, Representation theorems for some operator ideals, J. London Math. Soc. 39 (1989), no. 2, 324-334.

[15] F. COBos ANd A. SEgurado, Limiting real interpolation methods for arbitrary Banach couples, Studia Math. 213 (2012), 243-273.

[16] R. A. DeVore, S. D. Riemenschneider And R. C. Sharpley, Weak Interpolation in Banach Spaces, J. Funct. Anal. (1979), no. 33, 58-94. 
[17] D. E. Edmunds AND B. OPIC, Limiting variants of Krasnosel'skil's compact interpolation theorem, J. Funct. Anal. 266 (2014), no. 5, 3265-3285.

[18] W. D. Evans AND B. OPIC, Real Interpolation with Logarithmic Functors and Reiteration, Canad. J. Math. 52 (2000), no. 5, 920-960.

[19] W. D. Evans, B. OpIC AND L. PICK, Real Interpolation with Logarithmic Functors, J. of Inequal. \& Appl. 7 (2002), no. 2, 187-269.

[20] F. FEHÉR AND G. GRÄSSLER, On an extremal scale of approximation spaces, J. Comput. Anal. Appl. 3 (2001), no. 2, 95-108.

[21] P. Fernández-Martínez, A. Segurado and T. Signes, Compactness results for a class of limiting interpolation methods, Mediterranean J. Math., 2016, DOI:10.1007/s00009-015-0667-3

[22] P. FERnÁNDEZ-MARTíneZ AND T. Signes, Real interpolation with slowly varying functions and symmetric spaces, Quart. J. Math. 63 (2012), no. 1, 133-164.

[23] P. FERnÁNDEZ-MARTíneZ AND T. Signes, Reiteration theorems with extreme values of parameters, Ark. Mat. 52 (2014), no. 2, 227-256.

[24] P. FernándeZ-MartíneZ And T. Signes, Limit cases of reiteration theorems, Math. Nachr. 288 (2015), no. 1, 25-47.

[25] P. Fernández-Martínez and T. Signes, A Limiting Case of Ultrasymmetric Spaces. Preprint, http://webs.um.es/pedrofdz/miwiki/doku.php?id=research

[26] S. G. KRein, Ju. I. Petunin, And E. M. Semenov, Interpolation of Linear Operators, Translations of Mathematical Monographs, vol. 54, American Mathematical Society, 1982.

[27] A. Pietsch, Approximation spaces, J. Approx. Theory 32 (1981), no. 2, 115-134.

[28] E. Pustylnik, Ultrasymmetric Spaces, J. London Math. Soc. 68 (2003), no. 2, 165-182.

[29] E. Pustylnik, A new class of approximation spaces, Rend. Circ. Mat. Palermo 2 (2005), no. 76, 517-532.

[30] E. PustyLniK, Ultrasymmetric sequence spaces in approximation theory, Collect. Math. 57 (2006), no. 3, 257-532. 